\title{
Bladder instability in patients with prostatic hypertrophy
}

\author{
RODNEY A. APPELL \\ M.D. \\ Department of Urology, The London Hospital, London, England EI IBB, and Department of Urology, \\ Louisiana State University Medical Center, New Orleans, Louisiana, U.S.A. 70112
}

\begin{abstract}
Summary
In 29 patients with urinary obstruction due to prostatic enlargement, medium-fill water cystometry was performed before prostatectomy and again 3 months after. A high incidence of detrusor hyperreflexia was observed pre-operatively, but findings were essentially normal 3 months after resection of the prostate. Possible mechanisms to explain these findings are developed. However, it was clear that the cystometric findings were not related to prostatic size.
\end{abstract}

\section{Introduction}

The precise cause of urinary retention associated with prostatism is not clear. The detrusor response to outflow obstruction is varied. It has been previously demonstrated that prostatic bulk is one component in the mechanism of bladder outflow obstruction (Appell et al., 1980), as it may constitute a barrier to low-pressure urinary flow which is unaffected by maximal urethral myogenic relaxation. However, the clinical degree of prostatic enlargement is poorly related to the severity of outflow obstruction (Turner-Warwick et al., 1973). Uroflowmetry (Shoukry et al., 1975), combined urodynamic (Turner-Warwick and Whiteside, 1970), and uroradiological (Shopfner, 1965) studies have made inroads into the understanding of obstructed micturition.

The detrusor responds to outflow obstruction in a variety of patterns and the question arises whether these differing patterns represent different reactions to the same mechanical obstruction or represent different stages in the development of the disordered vesico-urethral function. The purpose of this study was to assess detrusor function during clinical mechanical obstruction of bladder outflow by an enlargement of the prostate.

\section{Patients and methods}

Twenty-nine patients with clinical prostatic enlargement were studied at the time of proposed

Requests for reprints: Director, Urodynamics Unit, Department of Urology LSU Medical Center, 1542 Tulane Avenue, New Orleans, Louisiana, U.S.A. 70112. transurethral prostatic resection (TURP). Eightee of these had been admitted in urinary retentio while the remaining 11 had varying degrees of prostatism. None of the patients was taking ans medication and none received pre-study medicatio None of the patients presented evidence of neur\& logical disease.

Detrusor reflex function was assessed by means ơ room temperature medium-fill water cystometry performed in the supine position through a 12-4 (Charrière) catheter containing two $1-\mathrm{mm}$ perfusios apertures. Perfusion pressures were monitored by $\mathbb{Q}$ standard side-arm transducer and displayed ono $\mathrm{X}-\mathrm{Y}$ recorder.

All patients had repeat cystometry 3 months TURP.

\section{Results}

Histological examination of the resected prostat tissue revealed benign hyperplasia in all cases and aft pre-operative urine cultures showed no growth $\overrightarrow{\text { ㅇ }}$ bacteria. Before TURP, cystometry revealed detrus क्ष hyperreflexia in $12 / 18$ patients with urinary retentio and in 6/11 patients with prostatism (Table 19. Normal cystometry implied normal sensation of fullness and the presence of a detrusor reflex which could be voluntarily suppressed on comman $\$$ Detrusor hyperreflexia was defined as a detrusorr reflex evoked at low bladder distention which coug not be voluntarily suppressed, while detrusor areflexia was defined as the absence of the detrus or reflex during bladder filling. Cystometry performet 3 months after TURP (Table 1) demonstrated no. detrusor hyperreflexia in any patient who had beeg in urinary retention before TURP. However, $1 \%$ of the patients not in retention before TURP wit detrusor hyperreflexia continued to manifest detrus@્ hyperreflexia postoperatively.

No relationship could be found between the cystometric findings and prostatic size.

\section{Discussion}

The results of cystometry in this group of patien $\overrightarrow{\mathrm{B}}$ 
TABLE 1 Cystometry in patients before and 3 months after transurethral prostatic resection (TURP)

\begin{tabular}{lccc}
\hline Patient status $(n)$. & No. before & No. after & Prostatic weight $(\mathrm{g})$ \\
\hline (a) in urinary retention (18) & 12 & 0 & $11 ; 12 ; 15 ; 16 ; 18 ; 18 ; 18 ; 19 ; 22 ; 25 ; 25 ; 35$. \\
$\begin{array}{l}\text { - hyper-reflexia } \\
\text { - areflexia }\end{array}$ & 2 & 2 & $11 ; 38$. \\
- normal & 4 & 16 & $10 ; 22 ; 30 ; 70$. \\
(b) with prostatism (11) & & & $11 ; 15 ; 18 ; 18 ; 34 ; 38$. \\
- hyper-reflexia & 6 & 1 & $12 ; 16 ; 24 ; 30 ; 30$. \\
- areflexia & 0 & 0 & \\
- normal & 5 & 10 & \\
\hline
\end{tabular}

support the findings in prior studies utilizing water cystometry (Andersen, 1976) and gas cystometry (Andersen and Bradley, 1976) of a high incidence of detrusor hyperreflexia in patients with prostatic enlargement.

The high incidence of detrusor hyperreflexia in patients with bladder outlet obstruction due to prostatic enlargement but no obvious neurological disease may be triggered by anatomical distortion of the heavily sensory innervated posterior urethra. Andersen and Bradley (1976) likened this compression effect on sensory nerve endings to an entrapment neuropathy. If this were true, surgical reduction of the prostatic mass causing the compression would be expected to decompress the nerve endings and allow a change in the detrusor reflex function. This is precisely what was found when cystometry was performed 3 months after surgery, i.e. a return to a normal cystometric response. This is further supported by the recent study by Rao et al. (1979) who found that $60 \%$ of men subjected to prostatectomy had unstable bladders, but that $82 \%$ had normal studies several months after prostatectomy.

This study, however, clearly demonstrates that prostatic size alone does not relate to the cystometric findings of detrusor hyperreflexia. The interaction of smooth muscular tone of the posterior urethra under sympathetic nervous control and the prostatic mass is involved in production of outlet obstruction in this patient group, which helps to explain why patients with a lesser degree of prostatic enlargement may develop urinary retention while others with massive prostatic enlargement do not
(Appell et al., 1980). The detrusor instability found in these patients appears to be related to the total outlet resistance and not to prostatic mass effect alone, and helps to explain the variety of patterns of detrusor response to outflow obstruction.

\section{Acknowledgments}

The expert technical assistance of Ms Joanna Caprera, L.P.N. is greatly appreciated.

\section{References}

ANDERSEN, J.T. (1976) Detrusor hyperreflexia in benign intravesical obstruction. Journal of Urology, 115, 532.

ANDERsEN, J.T. \& Bradley, W.E. (1976) Detrusor and urethral dysfunction in prostatic hypertrophy. British Journal of Urology, 48, 493.

Appell, R.A., England, H.R., Hussel, A.R. \& McGuire, E.J. (1980) The effects of epidural anesthesia on the urethral closure pressure profile in patients with prostatic enlargement. Journal of Urology, 124, 410.

RaO, M.M., Ryall, R., Evans, C. \& Marshall, V.R. (1979) The effect of prostatectomy on urodynamic parameters. British Journal of Urology, 51, 295.

SHOPFNER, C.E. (1965) Cystourethrography and evaluation of method. American Journal of Roentgenology, 95, 468.

Shoukry, I., SusSet, J.G., Elhilali, M.M. \& Dutartre, D. (1975) Role of uroflowmetry in the assessment of lower urinary tract obstruction in adult males. British Journal of Urology, 47, 559.

TURNER-WARWICK, R.T. \& Whiteside, C.G. (1970) Investigation and management of bladder neck dysfunction. In: Modern Trends in Urology No. 3 (Ed by Riches, Sir E.), pp. 295-311. Butterworth, London.

TURNer-WarWick, R., Whiteside, C.G., ARnOld, E.P., Bates, C.P., Worth, T.H.L., Milroy, E.G.J., Webster, J.R. \& WEIR, J. (1973) A urodynamic view of prostatic obstruction and the results of prostatectomy. British Journal of Urology, 45, 631. 